\title{
Hurdles of Pursuing a Doctoral Degree in Africa: Challenges and Realities
}

\author{
Norman A.S. King* \\ University of Dodoma and University of Iringa
}

*Corresponding Author: Norman A.S. King, University of Dodoma and University of Iringa

\begin{abstract}
Doctoral degree is perceived as the highest level of certified formal education. It is the source of valuable contribution to the new knowledge. However, attaining doctoral degree in most institutions is a challenging exercise. The challenges emerge from many facets accumulated as strength or weakness of students and supervisors. This paper eludes some challenges that are experienced during the pursuance of PhDs in most African countries. The factors could be globally, however all the interviewees were from Africa, and some were educated in Africa and some beyond Africa. The study has utilised the gathering of professors and senior lecturers who participated in the training of various research methods tailed for supervisors of $P h D$ students in Kampala, Uganda. Hence, the study is a case study which utilised interview, observation and open questionnaire as the major data collection strategies. The respondents were divided into five thematic groups of five respondents, and the answers were on agreement of the entire group. Each group was requested to enumerate challenges students face during the pursuance of PhD program, noting that the supervisors of today were students in the past. The training was conducted for two weeks, hence the study benefited from accessing academicians in their togetherness. We conclude that challenges that face students are essentially divided into two major groups. Those related to the weakness of the students geminating from their backgrounds, which include absence of proper mentorship on research; and those related to the weakness of supervisors geminating from weak mentorship during acquisition of the past degree awards, and those related with lack of exposure on varied methods of accomplishing research work for the award of doctoral degree.
\end{abstract}

Keywords: Research, students, doctor of philosophy, supervisors

\section{INTRODUCTION}

Doctor of philosophy is popularly known as PhD. It is the highest certification of academic degrees. A $\mathrm{PhD}$ is essentially attained after completion of varied modules pending the nature of the program. Nevertheless, the most common quality of any $\mathrm{PhD}$ degree is research that contributes knowledge to the existing one. In this regard, it can shape the present knowledge or create a new one. Hence, the world over, researches that lead into attaining a degree of doctor of philosophy has varied qualifications. In some institutions one would require a master degree of a certain speciality, while in some institutions one would require any master degree assessed by the respective organ as sufficient for the pursuance of the degree of philosophy. In some other institutions, master degree is not a prerequisite but a good bachelor degree, such as first class or upper second class as named in most developing countries, and high distinction or distinction as named in most developed countries.

There are several types of research. However, we feel that the mere mention of this type would suffice since the major theme is to expound challenges facing students pursuing doctoral programs.

Before we deviate into our study, it is critical that we cover in a nutshell on the various types of research to culminate common understanding on where and how we face difficulties in pursuing the $\mathrm{PhD}$. Several authors have narrated on some specific types of research which include:

1) Pure research or fundamental research refers to investigations undertaken primarily of the sake of knowledge itself. In this type of research, there is no consideration of commercial gains. But envisaging knowledge is crucial.

2) Applied research, is primarily directed towards solving some specific problem which has a practical purpose. Typically applied research finds uses for results of Pure Research. Development of transistor, computer chips etc are examples of applied research. 
3) Product research, which attempts to uncover new product ideas which will meet the requirements of current as well as prospective customers. In expanding product research, efforts may be directed toward new and different products, new uses for present products or utilization of a byproduct.

4) Manufacturing Research, is directed towards development of tools, equipment, and machineries that can lead into reducing the cost of production while increasing the products through reduced unit of cost of production.

5) Materials research. Materials researchis linked with both product research and manufacturingresearch as the discovery of new materials has impact on both. The jet andmissile age has put great emphasis on materials research leading to success of many space programs. Superplastic steel has made possibility of castingcomplex shapes such as precision gears by eliminating the need of costly final machining and joining commonly required with very hard forged steels.

6) Market research and operation research, is a systematic, objective collection and analysis of data about a particular target market, competition, and/or environment. It always incorporates some form of data collection whether it is secondary research (often referred to as desk research) or primary research which is collected direct from a respondent. The purpose of market research is to optimize sales of the respective product or to increase segment of customers on the products.

It is from these varied types of researches that this study entails to investigate hurdles of pursuing a $\mathrm{PhD}$ as opined by various $\mathrm{PhD}$ holders and supervisors.

\subsection{Statement of the Problem}

The trends of performance of $\mathrm{PhD}$ students in various African institutions in Africa have varied experience. Some do graduate exactly on the set time; some after a year from whence was supposed to graduate; some even after two to eight years after the time set for accomplishing the studies. The narrations provided by most academic institutions prospectus provide a more pragmatic view as to what is the viability of the $\mathrm{PhD}$ program. Generally, there are five major stages of pursuing a $\mathrm{PhD}$. The first is proposal preparation, which include concept note or synopsis preparation. The second is defending the proposal before the learned panel. The third is data collection. The fourth report writing, which include analysing data, coding and interpreting. The fifth is defending the dissertation or thesis before the learned panel, which is popularly known as viva voce. The generic named stages necessarily require students to accomplish the programs in the scheduled time. Yet it is not the case, students complete the program differently. The issue of concern is what makes that disparity? Is it the weakness of the students? Is it the weakness of the supervisors? Is it the institutions administration? Hence, need to investigate hurdles for pursuing a $\mathrm{PhD}$ degree.

\subsection{Objectives of the study}

The main objective of the study was to investigate factors hindering or promoting the thorough pursuance of a PhD program in various universities. The main objective was subdivided into three minor objectives.

a) To find out the students contribution in hindering or fostering the completion of the program?

b) To find out the supervisor's contribution in promoting or hindering the completion of the program?

c) To investigate any other factors promoting or hindering the completion of the $\mathrm{PhD}$ program.

The objectives were substantiated through three main questions.

i. What do you consider to be factors hindering or promoting the completion of $\mathrm{PhD}$ ?

ii. What do you think are the hindrances pegged to the student in completing the $\mathrm{PhD}$ ?

iii. What do you think are the hindrances pegged to the supervisor in completing the $\mathrm{PhD}$ ?

iv. What do you think are the institutional factors hindering the completion of the $\mathrm{PhD}$ program? 


\subsection{Significance of the Study}

The study provides the articulation of the factors, which promotes and those which hinders the thorough performance of the $\mathrm{PhD}$ program as contributed by the tripartite: students, supervisors and the institutions arrangement. It further provides recommendations on how best could the tripartite do to foster the completion of the program. It sets an agenda for nourishing the program and equally availing competence based mode of weighing the strength of both the students and the supervisors.

\subsection{Methodological Assumptions}

The study assumes that the sample of the senior lecturers and professors met in Uganda for the study of research methods on quantitative, qualitative and mixed methods represent a proper sample for this study. Further, that the sample has been obtained on purposeful sampling and that all respondents were $\mathrm{PhD}$ holders and thus provide a considered viable opinion from what they have faced as students and from what they face as supervisors.

\subsection{Design of the Study}

The study emulates the case study design as only professors and senior lecturers who hold a $\mathrm{PhD}$, and who were attending training organized by OSSREA in Kampala Uganda participated in the research. It has used a qualitative approach in transcribing and interpreting the data. Descriptive analysis is used in presenting the data. We have also used charts availed from the nominal coded similar responses to expound and give meaning to the findings. Norman (2013) asserts that most researches do not attract the attention of decision makers partly because they are not friendly to people who are not academicians. We know that researches are meant for consumption of both academicians, decision makers and the entire society hence it should be easy to understand hence presented in a manner that will attract easier interpretation.

\subsection{Sample and Sampling Procedure}

The sample was obtained through purposeful sampling as only trainees attending a workshop on research methodology course for senior academicians in East Africa participated. The attendees were from 16 different countries of Africa. The training was organized by OSSREA with her headquarters in Addis Ababa, Ethiopia. The total number of trainees were 25. In this study the participant who are the respondents were divided into five groups and thus the findings of this study are coded based on the five groups. We have treated each group response as the agreement of the entire group. Finally, we have amalgamated the responses as one sample case study to come up with the interpretation of findings that are worthy for consumption.

\section{LITERATURE REVIEW}

Various literature have emulated the pertinence of researches (Kothari, 2004; Saunders, 2013; Creswell, 2003). And some have gone further expounding on the importance of researches and qualities of researchers (Norman, 2012). In most case the seemingly most covered is the methodological aspects of research, types of research and the generic importance of it. Few have stemmed into narrating the hurdles that $\mathrm{PhD}$ students face in accomplishing the program. We seem to have taken for granted that things are as usual much as the students will finally graduate. The difficulties that student face have not been much availed. We have taken for granted that supervisors know their job, yet we cannot tell where they have acquired knowledge for supervising. Hence, some few questions are worthy. Is supervising dissertations and thesis a gift? Is it an automatic career? Is there any training for supervisors? Such questions calls for a deep understanding of the problems that students face in pursuing PhDs. Some literatures have expounded on the importance of research and procedural articulation. The list is huge and includes (Bell, 1999; Norman et al. 2013; Baxter and Tight, 2001; Dawson, 2002; Kumar, 2005). Some authors have made emphasis on students and how they should devout time to foster the research work. The list include (Krathwahl, 1988; Cryer, 2000; Norman et al, 2014; Norman \& Malangalila, 2013).

\section{ANALYSIS OF THE Findings}

The findings of the study has revealed many challenges which are considered facing the student pursuing doctoral degree. The essence of the factors and or challenges mentioned are critical because have been revealed by once students and now supervisors. The findings are in three major groups. 1) 
Those related to the students weakness. 2) Those related to the supervisors weakness and 3) those related to institutional arrangements on $\mathrm{PhD}$ program.

The responses of the findings were on three main groups, which are factors related to the weaknesses of the students, factors related to the weakness of the supervisors, and factors related to the institutional setup/program requirements.

Table1.Challenges that students face when pursuing the study

\begin{tabular}{|c|c|c|c|}
\hline S/No & Description of the challenges & Frequency & $\%$ \\
\hline 1. & $\begin{array}{l}\text { Failure of the supervisors to respond in time, which includes delay in reading thesis } \\
\text { or dissertations }\end{array}$ & 25 & 100 \\
\hline 2. & $\begin{array}{l}\text { Failure by supervisors to respond in time when reading proposals/synopsis and } \\
\text { concept note }\end{array}$ & 25 & 100 \\
\hline 3. & $\begin{array}{l}\text { Lack of consistence on the supervisors opinion when they have commented on } \\
\text { students work }\end{array}$ & 15 & 60 \\
\hline 4. & $\begin{array}{l}\text { Lack of exposure of supervisors on what it takes for a PhD. Most assume that } \\
\text { holding a PhD is enough }\end{array}$ & 15 & 60 \\
\hline 5. & Narrow Scope of disciplines on the part of supervisors & 15 & 60 \\
\hline 6. & Lack of formal training to the supervisors on how to supervise students. & 20 & 80 \\
\hline 7. & $\begin{array}{l}\text { Divergent views among the co-supervisors, makes it hard for students to } \\
\text { comprehend. }\end{array}$ & 5 & 20 \\
\hline 8. & $\begin{array}{l}\text { Allocation of supervision duties especially when there are large numbers of students, } \\
\text { it becomes difficult to comprehend }\end{array}$ & 5 & 20 \\
\hline 9. & $\begin{array}{l}\text { Supervisors do not have sufficient time because of their other non-academic work } \\
\text { load. }\end{array}$ & 15 & 60 \\
\hline 10. & $\begin{array}{l}\begin{array}{l}\text { Supervisors unfamiliarity with University and international research policies } \\
\text { /guidelines }\end{array} \\
\end{array}$ & 20 & 20 \\
\hline 11. & Weakness of students due absence of research knowledge & 15 & 60 \\
\hline 12. & Supervisors pulling in different directions & 5 & 20 \\
\hline 13. & Supervisors lack of capacity to know when research is ready & 5 & 20 \\
\hline 14. & $\begin{array}{l}\text { Antagonistic among the supervisors when they hold a divergent views amongst } \\
\text { them. }\end{array}$ & 5 & 20 \\
\hline 15. & Lack of financial resources to carry out credible research projects & 10 & 40 \\
\hline 16. & Supervisors inconsistency on the work & 20 & 80 \\
\hline 17. & $\begin{array}{l}\text { Improper base on research methods and or methodologies for students pursuing the } \\
\text { doctoral programs. }\end{array}$ & 20 & 80 \\
\hline 18. & $\begin{array}{l}\text { Lack of publication backroad (authorship) hence they focus on theoretical aspects } \\
\text { only }\end{array}$ & 20 & 80 \\
\hline 19 & inability of students to delineate their studies study areas properly & 20 & 80 \\
\hline 20. & Lack of financial resources to carry out credible research projects & 5 & 20 \\
\hline 21. & Students incapability to adopt the methods suggested/approaches by supervisors & 5 & 20 \\
\hline 22. & Time provided in the in the semester systems is not sufficient & 0 & 0 \\
\hline 23. & Weak student as they expect supervisors to do everything & 0 & 0 \\
\hline 24. & Untimely Response from student & 15 & 60 \\
\hline 25. & Student not able to justify her/his methodology & 20 & 80 \\
\hline 26. & Narrow Scope of disciplines on the part of students & 15 & 60 \\
\hline 27. & Supervisors Unavailability & 20 & 80 \\
\hline 28. & Supervisors laxity and Incompetence & 15 & 60 \\
\hline 29. & Supervisors disinterest & 10 & 40 \\
\hline 30. & Supervisors hidden motives or unpredictability & 10 & 40 \\
\hline
\end{tabular}

Source: Field work as opined in Kampala, Uganda.

Most interviews opine that supervisors are not prompt in managing the research projects. The supervisors, most of the time are not certain on accomplishing the reading of both concept note or synopsis, proposal and the entire research work.

It was noted that most interviewees gave experience of lack of predictability of completing the various stages of research. The stages include proposal preparation, defending of the proposal, feedback of errors or omissions on the proposal, which is normally done by the supervisor unless otherwise directed; data collection, cleaning of data, report writing, which include analyzing of data or 
information, harnessing the parts of research and finally defending the research paper before the panel.

Failure of supervisors to respond timely during the reading of proposals was an important factor, which seem to deter the pursuance of $\mathrm{PhD}$ for most students. It was evident that supervisors could not read proposals in respective time. R1 indicated that he submitted a proposal on February $10^{\text {th }}$, and the supervisor returned after six month. R4 had this to say, "I submitted my final proposal on 21 April, and the same was brought back in the month of March the following year. Reading is an art, it is anticipated that supervisors will always be oriented with practices that will bestow knowledge for enhancing performance of students.

Inability of students to understand and grasp their areas of interest is another barrier. Respondents indicated that some students, during their pursuance of $\mathrm{PhD}$ could not understand properly the areas they were working. This necessarily cements to what is called ignorance of students.

Generally, failure of supervisors to respond in time, which includes delay in reading thesis or dissertations attained $100 \%$. It was evident that all groups of respondents opined that they took long time in accomplishing their $\mathrm{PhD}$ because of laxity of supervisors in responding. This was however an opinion of the entire group. When the same question was tested to individuals, it was noted that 2 students who pursued their $\mathrm{PhD}$ in South Africa, and 3 who pursued their PhDs in Europe opined that supervisors were prompt.

Another factor which attained $100 \%$ score was failure of supervisors to respond in time when reading proposals and synopsis/concept note. It was evident that most supervisors do not read and thus respond timely. One respondents indicated that it took six months for the supervisor to respond to the proposal she submitted. Equally, some respondents indicated that it was hard to predict when to start collecting the data because one supervisor stayed with the proposal for 11 months.

The third most pressing factor which attained high score was lack of formal training to the supervisors on how to supervise students. This was supported by four groups out of five. It could be said that several training need to be conducted to allow senior lecturers at universities to acquire supervisory skills. What is happening each and every supervisor in most institutions have varied experience and exposure which is equal to his or her own experience. This factor was opined by $80 \%$.

The fourth factor was supervisors' inconsistency on the work they guide. Four focus group opined that there are lack of consistence on the part of supervisors. Most supervisors do not seem to remember the last opinion they gave to students. It was noted that at times a supervisor can make corrections on one chapter, say literature review, and finally give an okay. When a student submits the fourth chapter, admirably the same supervisor could correct the already marked work. This necessarily, provides a delay in accomplishing as one would not know when will the supervisor say it and abide to it. This factor attained $80 \%$. In addition, the unavailability of supervisors also attained $80 \%$. Most supervisors were perceived to get engaged in other activities for economic ventures other than supervising and or teaching students.

There are also factors which are of students' weakness. The respondents indicated that there are three major factors which had a score of $80 \%$. The factors are improper base on research methods and or methodologies for students pursuing the doctoral programs. Secondly, lack of publications background (practice) hence they focus on theoretical aspects only. Third inability of students to delineate their studies study areas properly. Fourth, student not able to justify her/his methodology. Most students have no foundation for research. Hence, they depend upon knowledge attained at the college one is admitted. It is imperative that colleges provide at least basic research methods course of about two weeks to provide proper knowledge to the students.

The fourth factor, which attained $60 \%$ is lack of knowledge on the theme that students choose. This is critical since lack of proper understanding of the theme may facilitate delay in accomplishing the program. In addition, it can give a task to the supervisors on eluding the theme instead of supervising. It is imperative that students choose areas of study to which their orientation if firm. There are several factors that fall both on supervisors, students and institutions.

Some universities indicate that one should submit a $\mathrm{PhD}$ proposal after nine months after admission to the program. This automates unnecessary delay since by mere having such instruction, a smart 
students who accomplishes the proposal in a month from the date of admission, cannot defend and thus should wait for eight months. Precisely, instructions should accommodate both fast learning students and slow learners. It could read, students should submit proposals not more than nine months from the date of admission. This would allow fast students to submit and finally defend the proposals as early as possible.

Some institutions have no schedule for defending the proposals, desertions and theses. It seems that, students defence is based on the mercy and grace of those who arrange the defence. One may submit the final manuscript in April and be called for defence inApril the following year. Several interviewee were of the opinion that arrangement of both external supervisors, local supervisors should be based on the competence of the supervisors. The rest of factors are summarised in the table above.

\section{CONCLUSION}

$\mathrm{PhD}$ is an important achievement for both the students, institutions sponsoring the students and for the development of our nations. Nevertheless, it is noted that there are hurdles that face students and supervisors engaged in the $\mathrm{PhD}$ programs. The obstacles are many but includes failure of the supervisors to respond in time, which includes delay in reading synopsis/concept note, research proposal, and thesis or dissertations. It includes lack of consistence on the part of supervisors when rendering their guidance to the students. Some supervisors are overtaken by other schedules hence they become unavailable as they pay no attention to the students. Further, it has been noted that some hurdles are institutional. These includes lack of proper time for defending the proposals, dissertations and or theses. There seem no clear schedules of PhD programs in some institutions. Mercy and favor seem to prevail for one to accomplish a program. Unnecessary long time located for proposal preparation, and other stages of a $\mathrm{PhD}$. In addition, some obstacles are on the part of students. These include, lack of knowledge on research methods; poor choice of area of study, which is backed by weak orientation of the student on the area. Further, lack of compliance of students on time (feedback) as instructed by the supervisors. It is concluded that the importance of a $\mathrm{PhD}$ includes providing knowledge on the researched area. Providing scientific propositions on the way forward on the area under investigation. Pending the parameters and the type of research, it could provide answers to the societal problems and thus a key to boosting national development. Hence, articulation on the procedures and time for undertaking it is inevitable. Supervisors should play a key role which is facilitate in nature to ensure students achieve their goal to the accomplishment of PhDs.

\section{ACKNOWLEDGEMENTS}

I would like to appreciate the participant of the research methods program tenured in Kampala Uganda, which was organised by the OSSREA for equipping knowledge to supervisors of $\mathrm{PhD}$ programs. Their participation in the research work rendered this achievement. The author is a professor of management, and lectures at University of Iringa, University of Dodoma and Teofilo Kisanji University. Prof. Norman has authored about 110 articles, 14 books, and has presented over 300 papers in various forums.

\section{REFERENCES}

[1] Bell, J. (1999). Doing Your Research Project: A Guide for First-time Researchers in Education \& Social Science, Oxford University Press. Oxford.

[2] Baxter L, Hughes, C. and Tight, M. (2001). How to Research, (Open University Press, Milton Keynes).

[3] Cryer, P. (2000). The Research Student's Guide to Success, (Open University, Milton Keynes).

[4] Dawson, C., (2002). Practical Research Methods, New Delhi, UBS Publishers' Distributors

[5] Kothari, C.R., (1985). Research Methodology- Methods and Techniques, New Delhi, Wiley, Eastern Limited.

[6] Krathwohl, D. R. (1988). How to Prepare a Research Proposal: Guidelines for Funding and Dissertations in the Social and Behavioral Sciences. Syracuse University Press.

[7] Kumar, R., 2005. Research Methodology-A Step-by-Step Guide for Beginners, (2nd.ed.), Singapore, Pearson Education.

[8] Norman, A.S.K (2017). The relevance of master degree in enhancing performance of workers in local government councils of Tanzania. A case of Mbeya district. Saudi Journal of Humanities and Social Sciences. Vol. 2(3), pp.254-259 
[9] Norman, A.S.K., Kyando, N., Massoi, L., (2014). The Challenges of Confidentiality and Anonymity in Pursuing Scientific Research. International of Social Science Research. Vol.2 (2), pp. 47-54

[10] Norman, A.S.K., Malangalila, S.K (2013). Preparing Scientific Articles: Some Hints and Tips. International of Social Science \&Interdisciplinary Research. Vol.2 (12), pp.90-95

Author's Biography

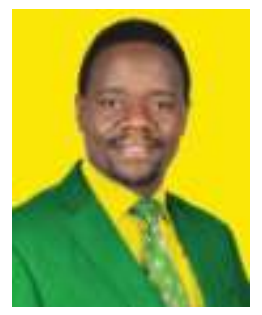

Prof. Norman A.S. King is a specialist in Elections Management, Business Management, Public Administration and Sustainable Economic Development. He attained his degrees at the Institute of Development Management (Mzumbe); Mzumbe University; Central Queensland University in Australia; Don Bosco University; and the Open University of Tanzania and attained ADPA; Graduate Diploma in Sustainable Development -economics; MBA (Finance and Banking); MBA(General Management); PhD (Public Administration); PhD (Business management). He has lectured in various institutions for 20 years including: Tumaini University, Iringa; Kampala International University; Teofilo Kisanji University, and Ghana University, Legon Centre for International Affairs among others. He has worked in several organizations ranging from local Non-Government Organizations (NGOs), regional organizations such as the Southern African Development Cooperation (SADC), and the East African Community (EAC). He has also worked in international organizations such as the Commonwealth and United Nations. With the Commonwealth he served as a Country representative to the CYP, and later Commonwealth Regional Coordinator, Africa region. With the United Nations, he chaired the UN Committee lower echelon on Human Rights in Portugal Lisbon, which was mandated to review article No. 1 of the United Nations Security Council. He also served as the UN Electoral Adviser in Timor East. He is the current President of Africa Network of Elections Observers and Peace Builders International, and has observed elections in over 26 countries. He is also a member of parliament of the United Republic of Tanzania and chairs the standing committee of Infrastructure which assumes oversight and advice to the government on roads, airports, ports, rail and communication.

Citation: Norman A.S. King. "Hurdles of Pursuing Doctoral Degree in Africa: Challenges and Realities."International Journal of Humanities Social Sciences and Education (IJHSSE), vol 5, no. 1, 2018, pp. 70-76. doi:http://dx.doi.org/10.20431/2349-0381.0501011.

Copyright: (C) 2018 Authors. This is an open-access article distributed under the terms of the Creative Commons Attribution License, which permits unrestricted use, distribution, and reproduction in any medium, provided the original author and source are credited. 